\title{
Linear and non-linear sea-level variations in the Adriatic Sea from tide gauge records (1872-2012)
}

\author{
Gaia Galassi, Giorgio Spada \\ Università di Urbino, Dipartimento di Scienze di Base e Fondamenti (DiSBeF), Urbino, Italy
}

\author{
Article history \\ Received April 2, 2014; accepted December 31, 2014. \\ Subject classification: \\ Sea-level rise, Tide gauge observations, Empirical Mode Decomposition, Adriatic Sea, Atlantic modes.
}

\begin{abstract}
We have analyzed tide gauge data from the Adriatic Sea in order to assess the secular sea-level trend, its acceleration and the existence of possible cyclic variation. Analyzing the sea-level stack of all Adriatic tide gauges, we have obtained a trend of $(1.25 \pm 0.04) \mathrm{mm} \mathrm{yr}^{-1}$, in agreement with that observed for the last century in the Mediterranean Sea, and an acceleration that is negligibile compared to the average global values. By means of the Ensemble Empirical Mode Decomposition technique, we have evidenced an energetic oscillation with a period of $\sim 20$ years that we relate with the recurrence of opposite phases in the Atlantic Multi-decadal Oscillation and North Atlantic Oscillation indices. We suggest that anomalously high sea-level values observed at all the Adriatic tide gauges during 2010 and 2011 can be explained by the rising phase of this 20 years cycle.
\end{abstract}

\section{Introduction}

Inter-annual sea-level variations are caused by several mechanisms. These include ocean mass variations, primarily related to the melting of present-day continental ice sheets and glaciers, and volume changes, mostly produced by thermo- and halo-steric processes [see, e.g. Slangen et al. 2011]. Tide gauges simultaneously observe both components [Spada and Galassi 2012]; in addition, they are sensitive to the vertical land movements originated by the solid Earth response to changes in the ocean and ice loads, or caused by tectonic movements and anthropic land subsidence [Cazenave and Llovel 2010]. Furthermore, ocean-atmosphere oscillations are responsible for cyclic sea-level variations; at a global scale, these are primarily related to the El Niño Southern Oscillation (ENSO), the North Atlantic Oscillation (NAO), and the Atlantic Multi-decadal Oscillation (AMO). Regional sealevel variability induced by interannual and interdecadal cycles can temporarily magnify or reduce the amplitude of long-term sea-level trend [Tsimplis et al. 2013].
The Adriatic Sea is a semi-enclosed basins communicating with the Mediterranean through the Otranto Strait. It is bounded by Italy on its northern and western sides and by Croatia, Bosnia, Slovenia, Montenegro and Albania on the eastern side (see Figure 1). Sea-level variability across the Adriatic Sea is a key issue principally because of its low-lying sandy shorelines. Most of the coastal zones are located at an elevation only slightly above (or sometimes even below) mean sea-level. A possible impact of sea-level rise is further enhanced by the presence, particularly along the coasts of the northern Adriatic Sea, of high-value economical activities and densely populated areas. In the Adriatic Sea, sea-level changes are mainly driven by steric effects [Tsimplis and Rixen 2002]. Since $\sim 1960$, an important role of atmospheric forcing has been evidenced by Tsimplis et al. [2012], who have also attributed a significant component of total sea-level change to land movements and to the coupling with the Mediterranean Sea through the Otranto strait. The influences of the ocean modes, as the NAO, on sea-level fluctuations in the Adriatic Sea have been first evidenced by Tsimplis and Josey [2001] and later reassessed by Tsimplis et al. [2013] and Landerer and Volkov [2013].

The problem of sea-level rise in the Adriatic Sea has been tackled in a number of studies, based on both tide gauges observation and oceanographic models. Since the tide gauges with longest records are located in the northern Adriatic (Venice and Trieste, Italy), most of the studies have focused on this area [see for example Ferla et al. 2007 and Masina and Lamberti 2013]. With the aim of assessing the vulnerability of coastal cities and infrastructures, several studies have investigated the frequency and magnitude of surges [see for example Pirazzoli and Tomasin 2002]. Sea-level measurements have been inter- 


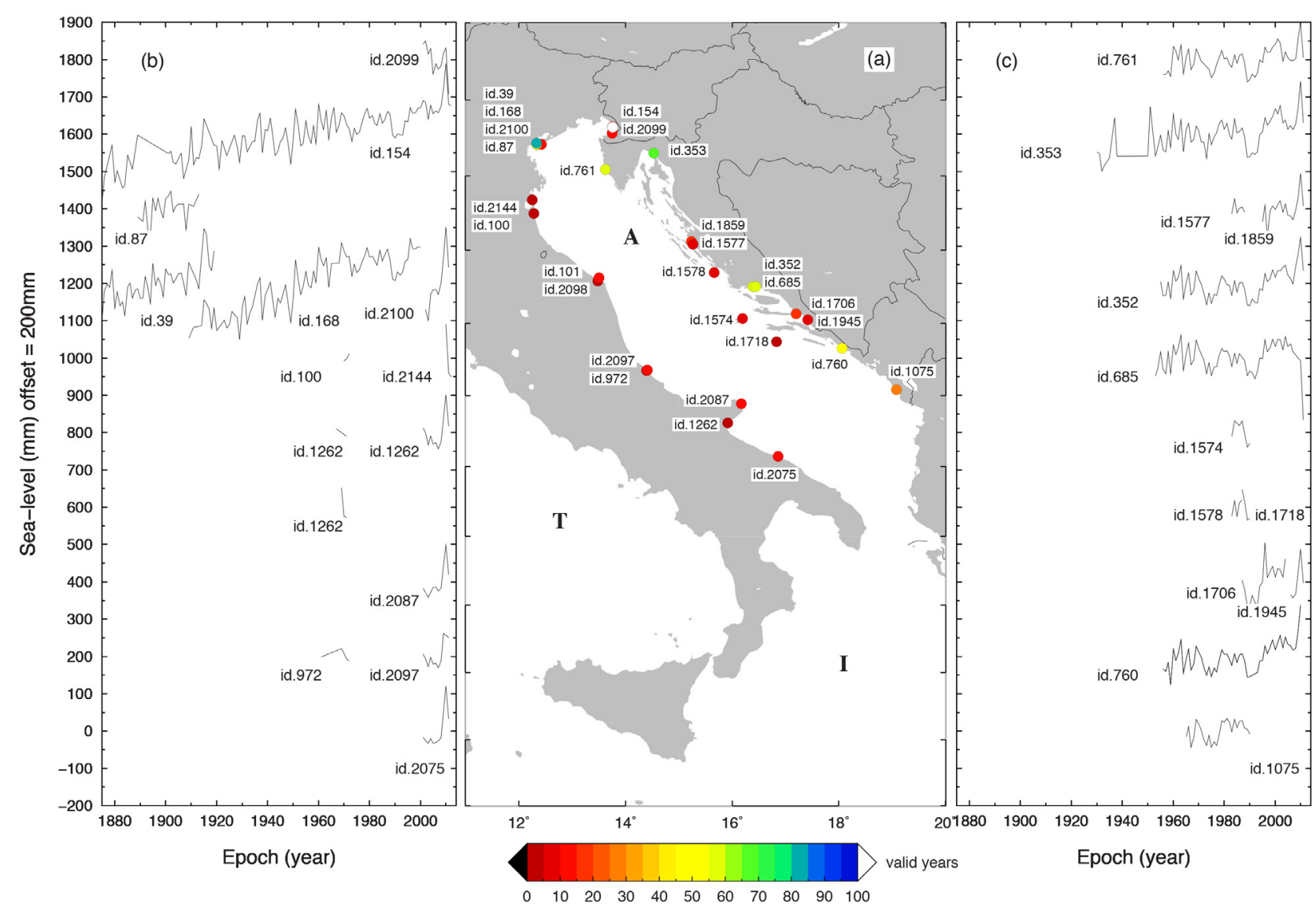

Figure 1. (a) Location of the RLR PSMSL tide gauges in the Adriatic Sea (Ids are also indicated). Letters A, I and T denote the Adriatic, the Ionian and the Tyrrhenian Seas, respectively. The number of valid years $\mathrm{N}_{\mathrm{val}}$ is key-coded by the color palette. (b) and (c) show the annual time series available at each station (see Table 1). The time series are shifted by $200 \mathrm{~mm}$ to facilitate visualization.

preted in terms of oceanographic and climatic processes using appropriate models [Tsimplis and Rixen 2002, Marcos and Tsimplis 2007, Tsimplis et al. 2012].

In this work, we consider all the tide gauge observations currently available for the Adriatic Sea since $\sim 1880$. Stacking the individual time series, we analyze the long term sea-level trend, its acceleration, and their anomalies within different time windows. We apply the Empirical Mode Decomposition (EMD) method to the Adriatic sea-level curve obtained by stacking, and, for the first time in this region, we enlighten the existence of cyclic sea-level variations related with the NAO and the AMO modes. The paper is organized as follows: in Section 2 we describe the sea-level data, the Atlantic modes data and the EMD approach; the results are presented in Section 3 and in Section 4 our conclusions are drawn.

\section{Data and methods}

\subsection{Sea-level data}

Our analysis is based on Revised Local Reference (RLR) tide gauge monthly and annual data from the Permanent Service for Mean Sea Level (PSMSL) [Holgate et al. 2012]. On August 2012, the RLR database was upgraded with the introduction of new data from 22 italian tide gauges: among these, seven are facing the
Adriatic Sea. Many of the newly introduced RLR Adriatic tide gauges have recorded more than 10 years of data, thus providing a significantly extended dataset that motivates our study. All the tide gauge data employed here have been obtained from the PSMSL web page (http:/ / www.psmsl.org/), and extracted from database on September 25, 2013. Since here we are mainly interested to non-linear sea-level variations, no correction has been performed for the effects of Glacial Isostatic Adjustment (GIA). Following the approach of Spada and Galassi [2012], no other corrections have been performed. The absence of steep changes in the tide gauge time-series suggests a negligible effect for co-seismic deformations. Furthermore, since local subsidence is not expected to drive cyclic effects on sea-level, no corrections for subsidence have been applied even in cases, like Venice, where its role is recognized to be particularly important [Carbognin et al. 2004].

The locations of the 30 RLR tide gauges considered in this study are displayed in Figure 1a, which also shows the number of valid years of data from each station (a valid year is one for which $\geq 10$ monthly averages are available). Figures $1 \mathrm{~b}$ and $1 \mathrm{c}$ show annual data at each station for the western and the eastern sides of the basin, respectively. Information about the tide gauges are listed in Table 1. Record lengths range between 3 
years (Porto Corsini and Porto Garibaldi, in northern Italy) and 138 years (Trieste), with this latter containing 116 valid annual records. The completeness of records varies between $33 \%$ (Ortona) to $100 \%$ for 14 stations out of 30. Altogether, the record of the RLR Adriatic tide gauges spans 141 years, starting in 1872 (Venezia Porto S. Stefano) and ending to present. Although following the PSMSL recommendation here we only analyse RLR tide gauge data, we note that for some northern Adriatic sites (e.g., Porto Corsini), the metric record is considerably more extended. This would probably merit efforts to update these records to the RLR standard.

To construct a sea-level curve representative of the whole time period cov- ered by the Adriatic tide gauges and to increase the signal-to-noise ratio, we have stacked the individual monthly time series. Stacking techniques are commonly used in seismic data processing [see e.g. Gilbert and Dziewonski 1975] and have been also employed in global sea-level studies [Trupin and Wahr 1990, Jevrejeva et al. 2006, Olivieri and Spada 2013]. At local scale, by an averaging approach equivalent to stacking, Scarascia and Lionello [2013] have constructed a synthetic sea-level curve for the North
Adriatic Sea starting from the longest tide gauge records available. Following Olivieri and Spada [2013], here the stack has been obtained by averaging, at each time step, the sea-level values available from the Adriatic tide gauges.

The curve resulting from the stack of Adriatic tide gauge monthly time series is shown in gray in Figure 2. Hereinafter, this curve will be referred to as the "AS curve". A cursory analysis of the AS curve has been performed by a linear regression (black line), which provides a rate of sea-level rise $\mathrm{r}_{\mathrm{AS}}=(1.23 \pm 0.05) \mathrm{mm} \mathrm{yr}^{-1}$ during the time period 1872-2012, where the uncertainty defines the $95 \%$ confidence level, according to statistics described by Spada and Galassi [2012]. However, even a cursory inspection reveals that the linear regression provides a poor description of the AS curve. Indeed, a 10-years moving average, shown by the red curve in Figure 2, suggests the existence of cyclic sea-level variations with a period of about $\sim 20$ years, which will be investigated further on.

The values of the sea-level trend and acceleration obtained from tide gauge time series generally vary significantly according to the time span considered [e.g., Olivieri and Spada 2013]. To study this sensitivity

\begin{tabular}{|c|c|c|c|c|}
\hline Station name & $\begin{array}{c}\text { PSMSL } \\
\text { Id }\end{array}$ & $\begin{array}{c}\text { Period } \\
\text { year-year }\end{array}$ & $\begin{array}{l}\mathbf{N}_{\text {val }} \\
\text { years }\end{array}$ & $\begin{array}{l}\mathrm{c} \\
\%\end{array}$ \\
\hline Ancona & 101 & $1967-1971$ & 2 & 40 \\
\hline Ancona II* & 2098 & $2001-2011$ & 11 & 100 \\
\hline Bakar & 353 & $1930-2011$ & 69 & 84 \\
\hline Bar $^{\star}$ & 1075 & $1965-1990$ & 26 & 100 \\
\hline Bari & 2075 & $2001-2011$ & 11 & 100 \\
\hline Dubrovnik & 760 & $1956-2010$ & 53 & 96 \\
\hline Gazenica & 1577 & 1983-1988 & 6 & 100 \\
\hline Koper & 1009 & 1962-1991 & 26 & 87 \\
\hline Luka & 1817 & $1992-2003$ & 11 & 92 \\
\hline Manfredonia & 1262 & $1969-1971$ & 3 & 100 \\
\hline Ortona & 972 & $1961-1972$ & 4 & 33 \\
\hline Ortona $\mathrm{II}^{\star}$ & 2097 & $2001-2011$ & 10 & 91 \\
\hline Ploce & 1945 & $2006-2011$ & 6 & 100 \\
\hline Porto Corsini & 100 & $1970-1972$ & 3 & 100 \\
\hline Porto Garibaldi` & 2144 & $2010-2012$ & 3 & 100 \\
\hline Rovinj & 761 & $1956-2011$ & 55 & 98 \\
\hline Split G. Luka & 352 & $1955-2011$ & 57 & 100 \\
\hline Split RT Marjana & 685 & $1953-2011$ & 56 & 95 \\
\hline Sucuraj & 1706 & $1987-2004$ & 17 & 94 \\
\hline Trieste & 154 & $1875-2012$ & 116 & 84 \\
\hline Trieste II $^{\star}$ & 2099 & $2001-2011$ & 11 & 100 \\
\hline Ubli & 1718 & $1987-1990$ & 4 & 100 \\
\hline Venezia P. Salute & 168 & $1909-2000$ & 83 & 90 \\
\hline Venezia P.S. Stefano & 39 & $1872-1919$ & 46 & 96 \\
\hline Venezia Arsenale & 87 & $1889-1913$ & 22 & 88 \\
\hline Venezia II* & 2100 & $2002-2011$ & 10 & 100 \\
\hline Vieste $^{\star}$ & 2087 & $2001-2011$ & 10 & 91 \\
\hline Vis-Ceska & 1574 & $1983-1990$ & 7 & 88 \\
\hline Zadar & 1859 & $1995-2011$ & 17 & 100 \\
\hline Zlarin & 1578 & $1983-1987$ & 5 & 100 \\
\hline
\end{tabular}

Table 1. Basic data of the Adriatic tide gauges considered in this study, listed in alphabetic order. Symbols $\mathrm{N}_{\mathrm{val}}$ and $\mathrm{c}$ denote, for each time series, the number of valid yearly records and the completeness (\%), respectively. Starred $\left(^{\star}\right)$ tide gauges are those introduced into the RLR PSMSL dataset on August, 2012. 


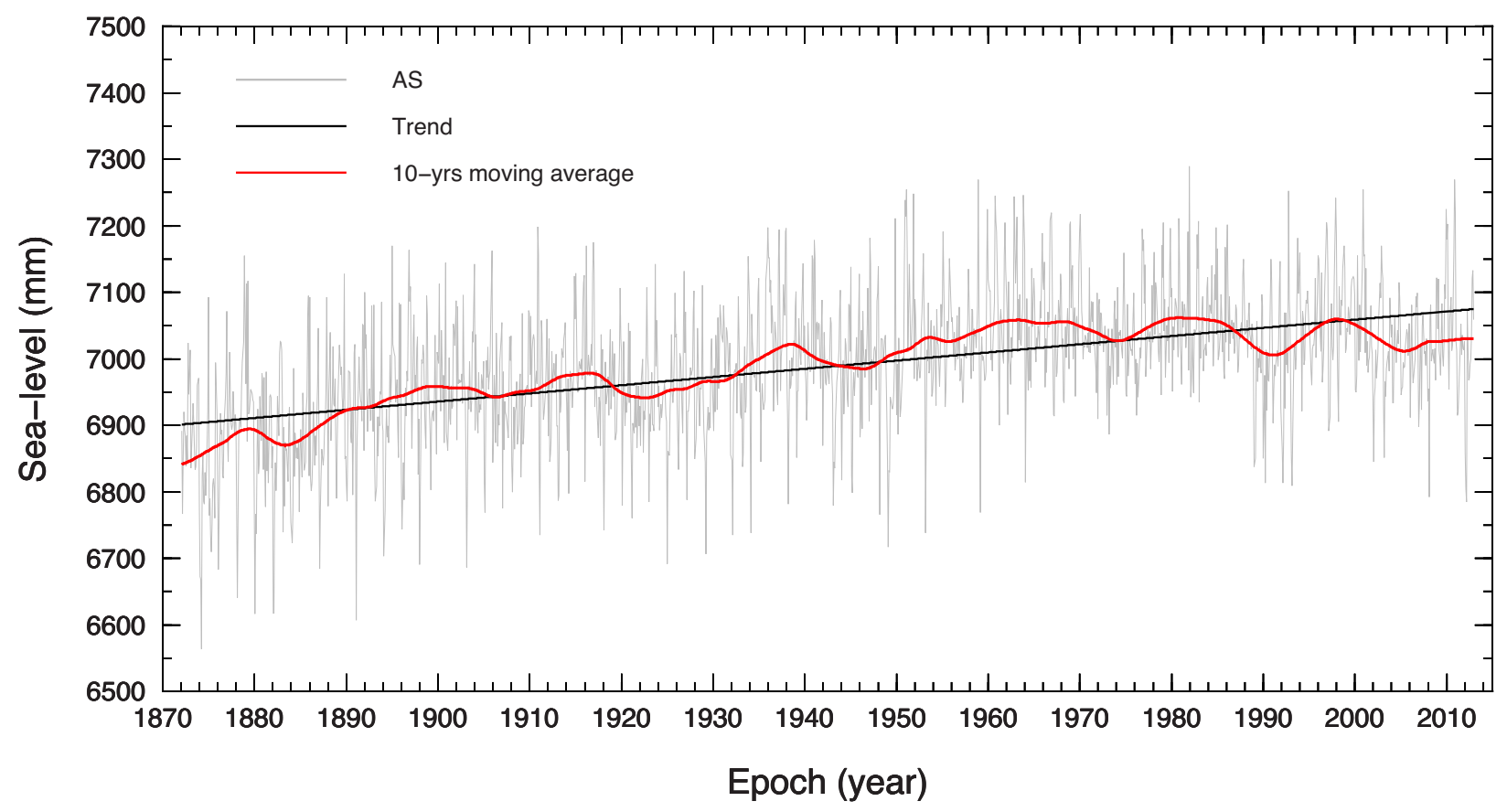

Figure 2. Stack of the Adriatic tide series from monthly data (AS curve). The black and the red curves show the best-fitting linear trend and the 10-years rolling average, respectively.

in the case of our AS, in Figure 3 we have performed a multi-scale dynamical analysis [MSDA, see Scafetta 2013] showing the average rate of sea-level change (3a) and the acceleration $(3 \mathrm{~b})$, obtained for different time windows centered at a given epoch (bottom axis). Rates and accelerations are computed as first and second dif-
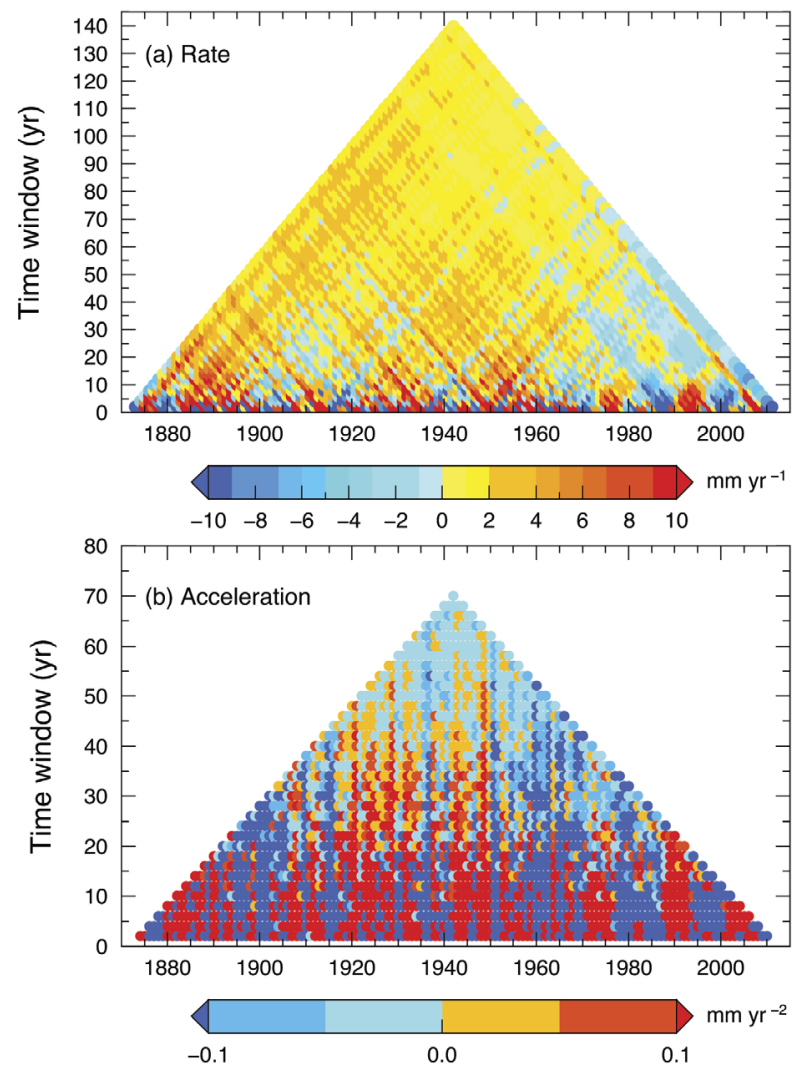

Figure 3. MSDA for the rate of sea-level change in (a) and acceleration (b) obtained by differencing the AS curve of Figure 2. ferences of the AS curve, respectively. The rate attains neatly positive values (yel- low and orange hues) only for windows of width $>60$ years. Negative trends (cyan) are observed, in particular, for windows of a few decades ( $<30$ years) after $\sim 1980$. For time windows exceeding 20 years, the acceleration ( $3 \mathrm{~b}$ ) shows values of the order of $10^{-1} \mathrm{~mm} \mathrm{yr}^{-2}$ with a relative uncertainty of $\sim 50 \%$, hence relatively small compared to the average global values [e.g., Olivieri and Spada 2013]. The time series that contain data from the last few years in Figure 1 , are all characterized by a neat sea-level high-stand occurring after year 2000. To focus on this feature, in the left part of Figure 4 we show the monthly records available for decade 2003-2012. For the same time span, the annual values are shown on the right. The red thick curves at the bottom show the stacked monthly and annual data. Even from a cursory inspection, the time series show broadly similar features. We find linear correlations as large as 0.9 , with average values in the range of $\sim 0.7-0.9$ for couples of overlapping tide gauge records longer than 50 years ( $95 \%$ confidence level). The correlation between the AS curve and records of Trieste and Venice is in the range $\sim 0.8-0.9$, at the same confidence level; while the correlation between the AS curve and the remaining tide gauge records varies in the average range $\sim 0.6-0.8$. Effects on sea-level from the difference in temperature and salinity between the eastern and the western Adriatic evidenced at seasonal time scale [e.g., Artegiani et al. 1997] are not visible at decadal periods.

From the monthly time series in Figure 4, two peculiar features appear, marked by the shaded rectangles. The first is a short-lived ( $\sim 2$ months) low-stand at the be- 


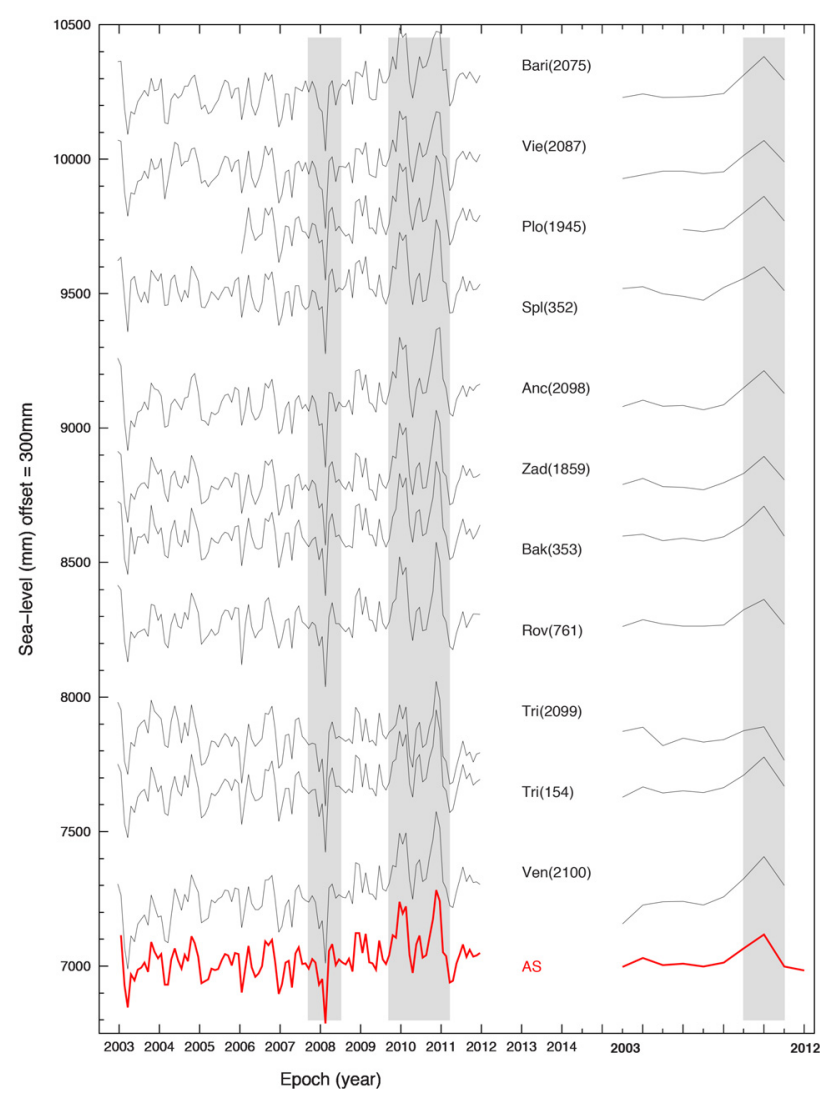

Figure 4. Adriatic time series (monthly on the left and annual on the right), and their stack (red) for the decade 2003-2012. The shaded rectangles mark the occurrence of the sea-level anomalies discussed in the text.

ginning of 2008, a feature that is not discernible in the annual averages. The second is represented by a couple of sea-level high-stands during the winters of years 2010 and 2011. In the annual records, these two peaks merge into a single maximum. The existence of this latter anomaly was previously detected for the whole Mediterranean Sea by Tsimplis et al. [2013], on the basis of observations from altimetry and model predictions of the steric component of sea-level change. In particular, they noted that during period 2008-2011, the mean absolute sea-level was $2-3 \mathrm{~cm}$ above the average altimetric datum, and they also remarked a very strong steric signal in the winter of 2011. Landerer and Volkov [2013], using both altimetry measurements (AVISO products) and gravity observations from the Gravity Recovery and Climate Experiment (GRACE), evidenced two sea-level anomalies in January 2010 and in December 2010, which reached an amplitude of 12 and $10 \mathrm{~cm}$, respectively. The occurrence of significant positive and negative sea-level anomalies in the past few decades was also evidenced by Raicich (2003) for the northern Adriatic.

\subsection{The Atlantic modes}

To investigate possible connections between sealevel variations and the ocean-atmosphere oscillations in the Adriatic Sea, henceforth we consider the NAO and the AMO Atlantic modes. The NAO index represents the difference between the normalized sea-level pressure in Lisbon (Portugal) and Stykkisholmur/Reykjavik (Iceland) since 1864 [Hurrel 1995]. A positive NAO index signifies an increased pressure gradient and stronger westerlies over the middle latitudes [Grossmann and Klotzbach 2009]. The AMO is a mode of variability occurring in the North Atlantic Ocean, defined from the patterns of sea-surface temperature once the linear trend has been removed. A positive AMO phase corresponds to an almost uniform warming of the North Atlantic [Enfield et al. 2001]. The existence of periodicities in the Atlantic modes $\mathrm{NAO}$ and AMO is well known and it is based on mechanisms of positive and negative feedbacks and of delay [Suarez and Schopf 1988]. In this framework, Grossmann and Klotzbach (2009) have recognized that the variability of convection due to salinity and temperature changes takes place in the seas facing Greenland, Iceland, and Norway, in the Labrador Sea and, to a lesser extent, in Mediterranean Sea.

The influence of the NAO on the Mediterranean sea-level has been the subject of various investigations. Jordà and Gomis [2013] have related the negative temperature trend in the Mediterranean Sea (in contrast with the global mean temperature) to the highly positive NAO phase dominating the 1960s to 1990s decades. Tsimplis and Josey [2001] have analyzed the link between the sea-level variability in Mediterranean and the NAO concluding that the strengthen-ing of the latter from the 1960s to the 1990s explains a significant part of the reduction in Mediterranean sea-level over this period. Tsimplis et al. [2013] have analyzed the effect of the NAO on sea-level in Mediterranean Sea during 19932011, outlining the mechanism through which this oscillation influences the sea-level variability. Calafat et al. [2012] have provided evidence of an anti-correlation between NAO and sea-level at Mediterranean tide gauges, particularly at decadal time scale. A link between the oscillation of sea-level record detected by the tide gauge of Venezia and the AMO was noticed by Scafetta [2013]. The simultaneous effects of NAO and AMO on the sea-level variability in the Mediterranean Sea has been previously investigated by Raicich [2012]. He has found a correspondence between the negative sea-level anomaly in the early 1970 s with a negative AMO and a positive NAO and a simultaneous shift in the positive sea-level anomaly in the mid 1990s with a positive AMO and a negative NAO.

Here, we use the station-based NAO indices produced by the NCAR Climate Analysis Section ${ }^{1}$ (https: / / climatedataguide.ucar.edu/climate-data/hurrell-northatlantic-oscillation-nao-index-station-based), based on 

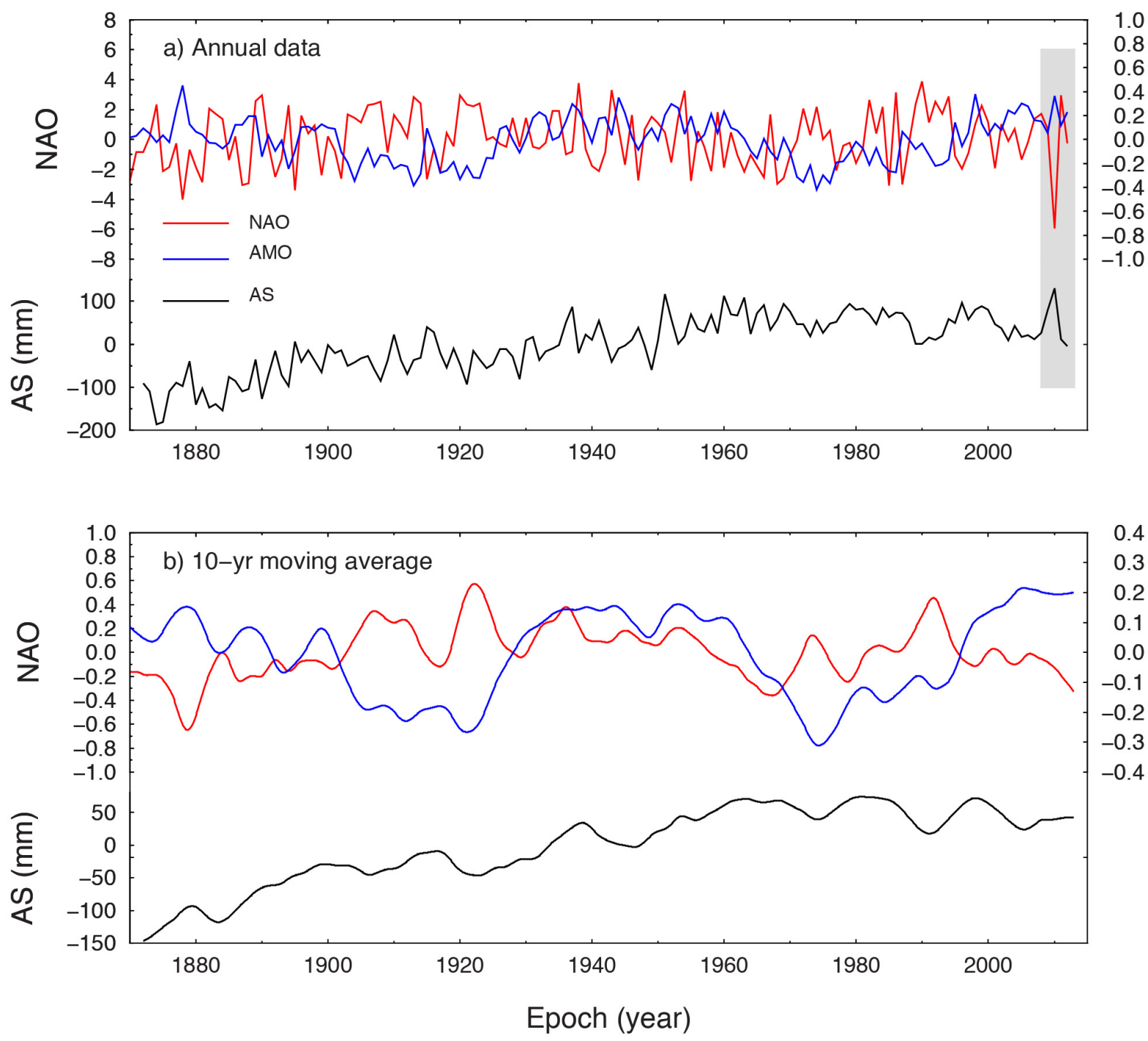

Figure 5. Comparison between NAO (red line), AMO (blue) and sea-level stack for the Adriatic tide gauges (AS, black). Frame (a) shows annual data for the three time series; while (b) shows their 10-years moving average. The 2010-2011 anomaly is marked by a shaded rectangle in (a).

Hurrel [1995], and the AMO index calculated at NOAA PSD from the Kaplan SST dataset 2 [Enfield et al. 2001]. The annual time-series for the NAO and the AMO are shown in Figure 5a by red and blue colors, respectively, while Figure $5 \mathrm{~b}$ shows the same time-series after the application of a 10-years moving average. The Adriatic sealevel stack is displayed at the bottom of each frame. The AMO and NAO indices are tightly interrelated, especially during recent decades, and characterized by a complex and non-stationary relationship [Walter and Graf 2002]. Grossmann and Klotzbach [2009] have shown that long-term positive (or negative) phases of the NAO correspond to negative (or positive) phases of the AMO, generally with a lag of several years.

\subsection{The EEMD method}

To establish the nature of the sea-level anomalies displayed in Figure 4 and to study the cyclic components suggested by the moving average in Figure 2, we have adopted the EMD method [Huang et al. 1998]. Non-lin- ear and non-stationary time series are decomposed into a sequence of $\mathrm{N}$ empirical orthogonal Intrinsic Mode Functions (IMFs) describing cyclic variations, not necessarily characterized by constant amplitudes and phases. Contrary to a simple regression, the EMD is not requiring a-priori assumptions about the functional expression of the regression model [Huang et al. 1998]. By the EMD, it is possible to isolate terms with dominating periodicities from the tide gauge record and obtain a residual, which reveals the long-term "natural trend" of the signal.

The EMD method has been previously used in sealevel studies by Ezer and Corlett [2012] and Ezer et al. [2013] to correlate variations in the Gulf Stream with variations in coastal sea level. Here we use an improved version of the EEMD method (the "ensemble EMD", see Wu and Huang [2009]), namely the Complete Ensemble Empirical Mode Decomposition with Adaptive Noise (CEEMDAN), described by Torres et al. [2011] and implemented in MATLAB. The EEMD method has been used by Breaker and Ruzmaikin [2011] to study 

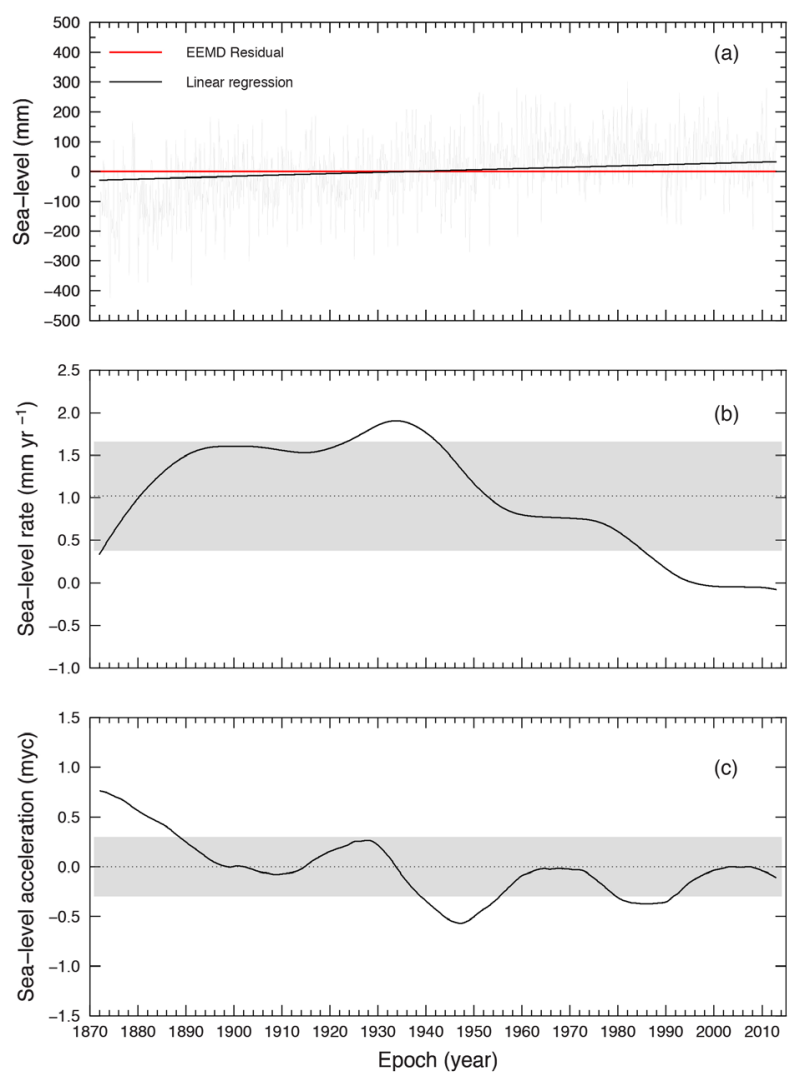

Figure 6. (a) EEMD residual (red) and its linear regression (black) for the AS (gray). (b) First difference (in $\mathrm{mm} / \mathrm{yr}$ ) and (c) second differences on the residual (in myc, where $1 \mathrm{myc}=\mathrm{mm} / \mathrm{yr} /$ century). Average values of first and second differences (dotted lines) and their uncertainty (shaded).

the San Francisco tide gauge time series and recently by Spada et al. [2014] to analyze the Nuuk/Godthab (Southwest Greenland) tide gauge record. As far as we know, the EEMD has never been exploited to analyze sea-level time series from Mediterranean tide gauges.

The EEMD requires the definition of two parameters. The first (Nsdt), is defined as the ratio of the standard deviation of IMF1 to the standard deviation of the original time series, and it determines the noise level. The second (NE), defines the number of realizations required to construct the IMFs. Proper values have been chosen by trial and error; here we use Nst $\mathrm{d}=0.44$ and NE $=300$. To avoid the "end effect" problem, a mirroring technique has been employed [Barnhart 2011]. To assess the uncertainty on the residual time serie, we have computed the mean variance of each IMFk obtained from the NE realizations, $\hat{\sigma}_{\text {IMFk }}^{2}$. The error on the residual is $\sigma_{\text {res }}=\sum_{\mathrm{k}=1}^{\mathrm{N}} \hat{\sigma}_{\text {IMFk }}^{2}$, where $\mathrm{N}$ is the number of modes.

\section{Results}

Figure 6a shows the EEMD residual (red curve) for the AS curve (grey, repro-duced from Figure 2), during time period 1872-2012. The linear regression on the residual gives a trend of $(1.25 \pm 0.04) \mathrm{mm} \mathrm{yr}^{-1}$, essen- tially coincident with the trend of the AS curve $\mathrm{r}_{\mathrm{AS}}=(1.23 \pm 0.05) \mathrm{mm} \mathrm{yr}^{-1}$ (black line). This value well matches the trend of the longest tide gauge record of Trieste $\left(1.25 \pm 0.06 \mathrm{~mm} \mathrm{yr}^{-1}\right)$ and it is in agreement with the sea-level rise in the Mediterranean Sea estimated for the $20 \mathrm{t} \mathrm{h}$ century by Tsimplis and Baker [2000], namely $1.1-1.3 \mathrm{~mm} \mathrm{yr}^{-1}$. Performing the EEMD analysis on a stack obtained without including the record of Trieste would essentially provide a residual with the same trend, confirming that the AS curve is representative of the whole Adriatic Sea.

The time variations of the sea-level trend and acceleration in the Adriatic Sea, shown in Figs. $6 \mathrm{~b}$ and 6c, are obtained evaluating the first and second differences of the EMD residual, respectively. Starting from $\sim 1900$, the rate of sea-level change has remained almost stable until $\sim 1950$, with values in the range of $1.5-2 \mathrm{~mm} \mathrm{yr}^{-1}$, comparable with the global secular rate of sea-level change [Spada and Galassi 2012]. In the ensuing four decades, it has declined signif- icantly to reach values $<0.5 \mathrm{~mm} \mathrm{yr}^{-1}$ after $\sim 1990$ and even slightly negative values during the last decade. The average value of the rate of sea-level change for the whole period is $(1.02 \pm 0.63) \mathrm{mm} \mathrm{yr}^{-1}$. The sea-level acceleration (Figure $6 \mathrm{c}$ ) has shown a strong variability during the time span considered, with a number of oscillations and no apparent trend. However, the acceleration of the residue has never exceeded the value of $0.01 \mathrm{~mm} \mathrm{yr}^{-2}$, somewhat less than the values obtained in the MSDA analysis in Figure 3b, which was based on the full and comparatively more noisy AS curve. The average acceleration is negative and its amplitude is negligible compared to the global average sea-level acceleration during the same time span [see values in Table 1 of Olivieri and Spada 2013].

The presence of cyclic sea-level variations in the Adriatic, qualitatively suggested by the stack of Figure 2, cannot be evidenced studying the EEMD residual. With this purpose, in Figure 7, we show the whole set of 10 IMFs obtained from the EEMD decomposition of the AS curve. The existence of a significant cyclic pattern in the IMFs is visually evident, with a period increasing with $\mathrm{k}$. The dominating period of each IMFs, obtained by standard Fourier transform methods, is shown in Figure 8a. A clear semi-annual periodicity is shown by both IMF2 and IMF3, while IMF4 is essentially an annual term. The periods of the remaining IMFs are regularly increasing with $\mathrm{k}$, approximately following a power law. The longest period $(\sim 70$ years) is that obtained for IMF10. Figure $8 \mathrm{~b}$ shows the values of the Fourier power spectra for the various IMFs, computed at the dominating periods shown in Figure 8a. The power is normalized by the 


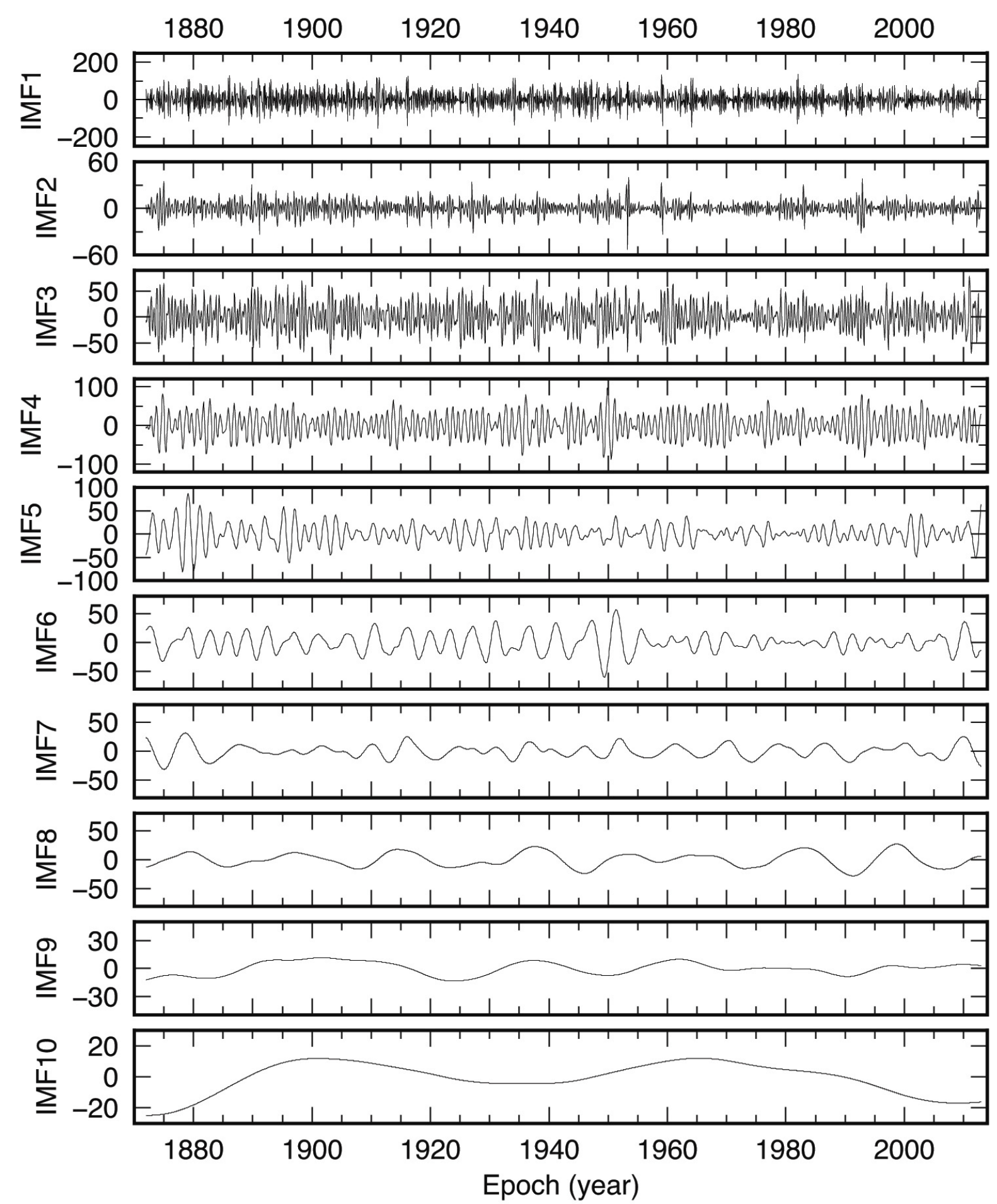

Figure 7. Image functions IMFk $(k=1, . ., 10)$ resulting from the EEMD analysis of the AS curve shown in Figure 2. Note the different scales on the y-axis.

value obtained for IMF2. The power attains the largest values for the semi-annual (IMF3) and the annual (IMF4) terms; for the remaining IMFs, it oscillates at relatively low levels. The power spectrum clearly shows that for periods in the range between $\sim 5$ and $\sim 40$ years the dominating oscillations are those described by IMF6 (4.8 years) and IMF8 (20.4 years). This latter periodicity ( 20 years $)$ was also qualitatively suggested by inspection of the 10-years moving average in Figure 2. The power of the oscillation with the longest period (IMF10, 70.5 years) exceeds that of all the other IMFs with $k>4$. This is a manifestation of the "red spectrum" problem in tide gauge observations illustrated by e.g. Sturges and Hong [2001], which substantially hinders the detection of a genuine sea-level trend from records shorter than $\sim 60$ years [Douglas 1997]. To establish the nature of the cyclic sea-level variations suggested by the EEMD analysis, we study the correlations between the NAO and AMO indices and the sea-level signals observed 

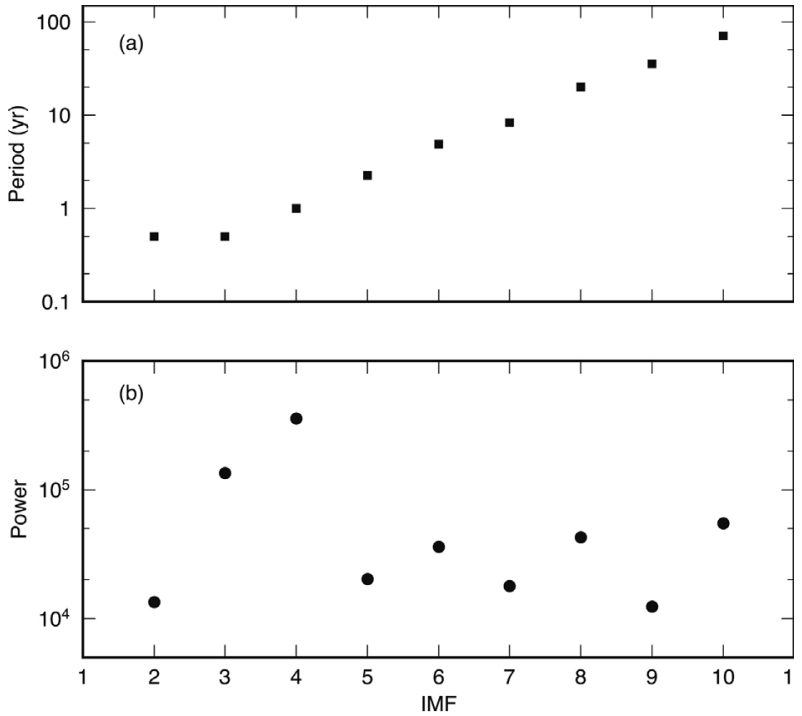

Figure 8. Fourier power spectrum analysis for the IMFk components of the AS curve. (a) Dominating period (in years); (b) Maximum power, normalized by the IMF2 maximum power. across the Adriatic Sea. The existence of an anti-correlation between AMO and NAO was already qualitatively clear from Figure $5 \mathrm{a}$ and it is even more evident from inspection of the smoothed curves in Figure 5b (relevant work supporting this anti-correlation has been quoted previously in Section 2.2). Similarly, a correlation between the AS curve and AMO and an anti-correlation between AS and NAO, is qualitatively suggested by the same figure. The correlation and anti-correlation phases are separated by periods of variable length, which are often close to $\sim 20$ years.

In Figure 9, the sample cross-correlations between the two Atlantic modes and the AS curve have been quantitatively evaluated using the method outlined by Box et al. [2008]. The three top frames refer to the time period 1880-2012, while the time window 2009-2012 is considered in the bottom; the correlations are shown at different time lags expressed in
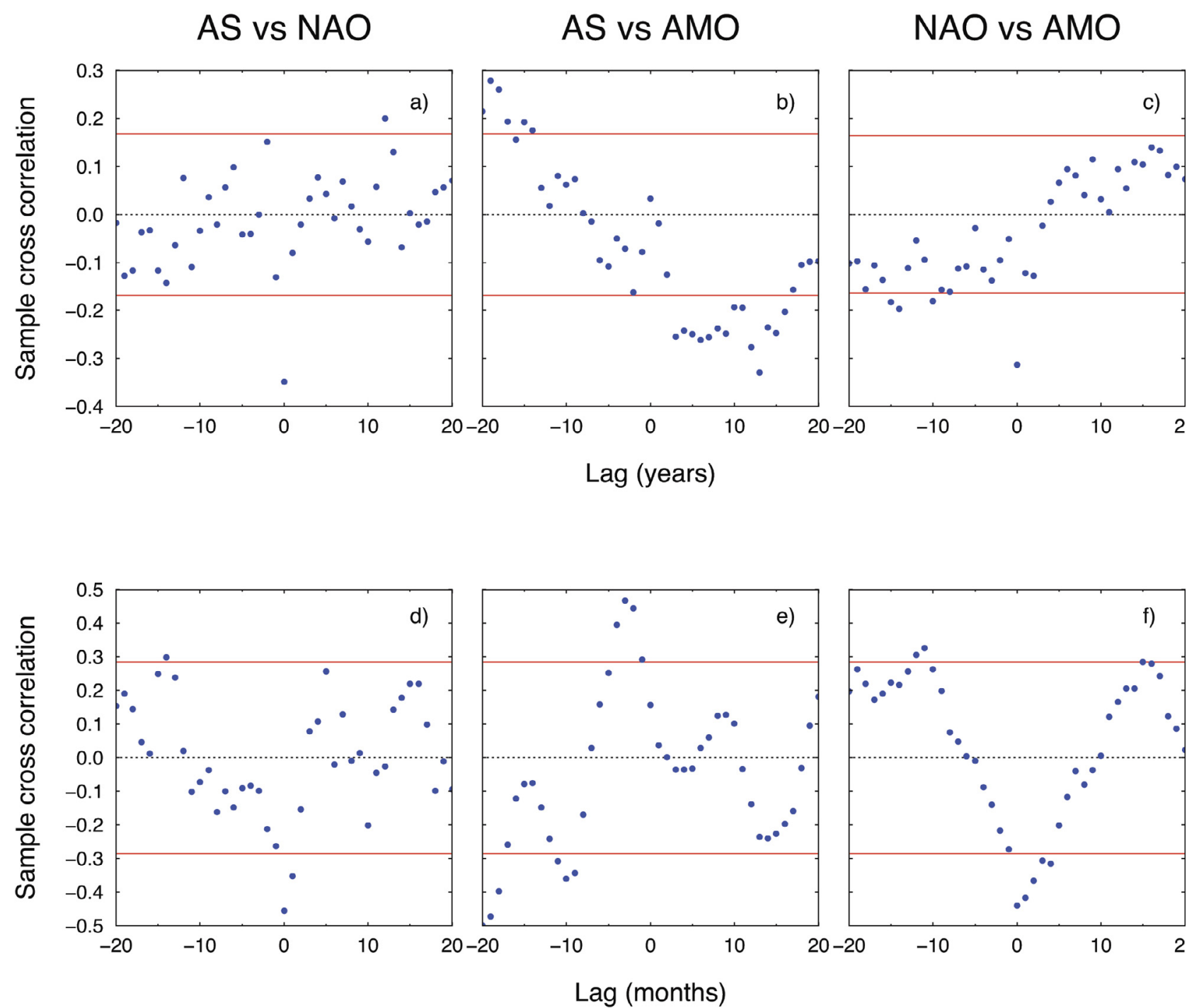

Figure 9. Sample cross correlation between AS, AMO and NAO (the $95 \%$ confidence intervals are denoted by red horizontal lines). Frames a), b) and c): whole period (1880-present) with annual data; d), e) and f): from 2009 with monthly data. 


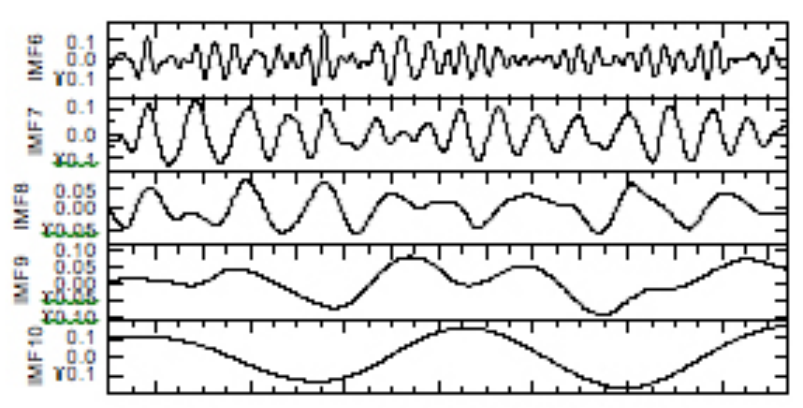

NAO

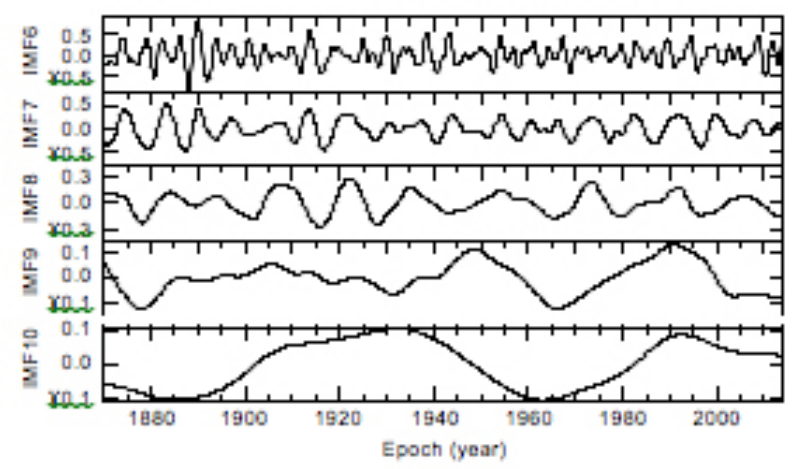

Figure 10. Image functions $\operatorname{IMFk}(\mathrm{k}=6, \ldots, 10)$ resulting from the EEMD analysis of the NAO and AMO indices.

years and months, respectively. The results show that an anti-correlation at lag 0 effectively exists between AS and NAO and between NAO and AMO for both the time windows considered ( $95 \%$ confidence level). This confirms our guess above based on Figure 5. A clear correlation pattern between AS and AMO is not evident for period 1880-2012 (Figure 9b), but during 2009-2012 we observe a significantly large correlation at lag $\sim 0$ (9e).

The EEMD analysis of the NAO and AMO indices, shown in Figure 10 and in Table 2, indicate that for the NAO the power is mostly concentrated in the IMF7 at a period $\mathrm{p}=7.8$ years. At a comparable period $(\mathrm{p}=\sim 9.2$ years), the AMO shows a peak in the power spectrum (IMF7). However, for the AMO, the maximum power is found at a multi-decadal time scale (IMF10, $\mathrm{p}=\sim 79$ years).

\begin{tabular}{lrrrr} 
IMF & \multicolumn{2}{c}{ NAO } & \multicolumn{2}{c}{ AMO } \\
& $\mathbf{p}(\mathbf{y r})$ & $\mathbf{n p w}$ & $\mathbf{p}(\mathbf{y r})$ & $\mathbf{n p w}$ \\
\hline 2 & 0.4 & 1 & 0.4 & 1 \\
3 & 0.6 & 14 & 0.6 & 21 \\
4 & 1.0 & 12 & 1.0 & 201 \\
5 & 2.4 & 11 & 2.5 & 127 \\
6 & 3.7 & 8 & 3.6 & 153 \\
7 & 7.8 & 22 & 9.2 & 744 \\
8 & 16.8 & 5 & 17.4 & 133 \\
9 & 49.3 & 2 & 52.3 & 325 \\
10 & 74.0 & 5 & 78.5 & $5.6 * 10^{3}$ \\
\hline
\end{tabular}

Table 2. Period ( $\mathrm{p}$, in year) and corresponding power (npw) resulting from the Fourier transform for each IMF of NAO and AMO indices (npw is normalized by the power of IMF2). For the EEMD analysis, we set $\mathrm{NE}=300$ for $\mathrm{AMO}$ and $\mathrm{NE}=400$ for $\mathrm{NAO}$.
The values of the periods found for the IMF7's of AMO and NAO suggest that opposite phases are met every $\sim 21$ years. We have further analyzed the relationship between these cyclic components, by a coherence test [Kay 1988], with a time window of 30 years, which has revealed a significant coherence ( $95 \%$ confidence) at a period of $\sim 22$ years, with a phase lag of $180^{\circ}$. Applying a coherence test to the AS curve and the AMO, a significant coherence is found at a period of 21.7 years, with a phase close to $0^{\circ}$. These results suggest that the $\sim 20$ years cycle shown by the IMF8 for the AS curve (see Figure 7) can be associated to the $\sim 21$ years cycle resulting from the combination of AMO and NAO.

The amplitude of the oscillations of the three signals considered here (AMO, NAO and AS) varies with time (see Figures 7 and 10), and the opposition or synergy of phases does not occur regularly. As evidenced in Figure 9, in 2009-2012 opposite phases for AMO-NAO and AS-NAO occurred simultaneously also accompanied by a synergic phase for AS-AMO; the 2010-2011 anomaly occurred exactly during this lapse of time and, furthermore, it fell inside the AMO warm phase. Alternate warm and cold phases for AMO have a long periodicity, of the order of that evidenced by the EEMD analysis (IMF10 $\sim 78$ years), well in excess of the $\sim 20$ years cycles shown by the AS curve. In North America and Europe, the warm AMO phase has been related to a decrease in sea-level pressure (SLP) and in sea surface temperature (SST) [see, i.e., Knight et al. 2006]. In the same regions, Sutton and Hodson [2005] have evidenced a role of AMO in modulating the summer boreal climate and the frequency of extreme events. A direct relationship between the AMO and the Mediterranean sea-level variations has not been pointed out yet. Nevertheless, the relationship between SST and SLP in the Atlantic Ocean and sea-level across the whole Mediterranean Sea is well documented [see, in particular Tsimplis and Josey 2001].

\section{Conclusions}

We have analyzed data from tide gauges in the Adriatic Sea for the time period between 1872 and 2012, using both traditional methods (linear regression, MSDA, first and second differences) and the EEMD. The time series show a high coherency and display anomalous low and high-stands during the last decade.Our main conclusions can be summarized as follows.

i) Linear regression on the Adriatic sea-level stack and on its EEMD residual indicates a secular sea-level trend of $(1.23 \pm 0.05)$ and $(1.25 \pm 0.04) \mathrm{mm} \mathrm{yr}^{-1}$, respectively, in agreement with the mean secular trend observed for the whole Mediterranean Sea. The sea-level acceleration, analyzed performing a MSDA on the AS 
curve and evaluating the second differences on the EEMD residual, shows relatively small values compared to the average global values.

ii) The EEMD analysis clearly reveals the annual and the semiannual periodicities in the AS curve, and shows a powerful oscillation with a period of $\sim 20$ years. The analysis on NAO, AMO and AS signals has shown that a negative phase of sea-level corresponds to a negative phase of the AMO and to a positive phase of NAO. The EEMD analysis suggests that the periodic occurrence of opposite phases in the AMO and NAO indices (with a period of $\sim 20$ years), correspond to the $\sim 20$ years cycle identified for the sea-level trend in the Adriatic Sea. The coincidence of AMO-NAO phase opposition and warm AMO phase could explain the anomalous sealevel high-stand detected during 2010-2011 and possibly help to forecast future anomalous sea-level fluctuations within the Adriatic Sea.

Acknowledgements. We thank Marco Olivieri for helpful discussions and useful suggestions. Thanks to the two anonymous reviewers to have stimulated in-depth analysis. All the figures have been drawn using GMT [Wessel and Smith 1998]. The italian tide gauges belong to the "Rete Mareografica Nazionale", managed by ISPRA (http://www.mareografico.it/). Funded by a DiSBeF (Dipartimento di Scienze di Base e Fondamenti, Urbino University) research grant (CUP H31J13000160001).

\section{References}

Artegiani, A., E. Paschini, A. Russo, D. Bregant, F. Raicich and N. Pinardi (1997). The Adriatic Sea general circulation. Part I: Air-sea interactions and water mass structure. Journal of Physical Oceanography 27 (8), 1492-1514.

Barnhart, B. L. (2011). The Hilbert-Huang Transform: theory, applications, development. Ph.D. thesis, University of Iowa.

Box, G., G. Jenkins and G. Reinsel (2008). Time series analysis: forecasting and control. John Wiley\& Sons.

Breaker, L. C. and A. Ruzmaikin (2011). The 154-year record of sea level at San Francisco: extracting the long-term trend, recent changes, and other tidbits. Climate Dynamics 36 (3-4), 545-559.

Calafat, F., D. Chambers and M. Tsimplis (2012). Mechanisms of decadal sea level variability in the eastern North Atlantic and the Mediterranean Sea. Journal of Geophysical Research: Oceans 117 (C9).

Carbognin, L., P. Teatini and L. Tosi (2004). Eustacy and land subsidence in the venice lagoon at the beginning of the new millennium. Journal of Marine Systems 51 (1), 345-353.

Cazenave, A. and W. Llovel (2010). Contemporary sea level rise. Annual Review of Marine Science 2, 145-173.

Douglas, B. (1997). Global sea leve rise: a redetermination. Surveys in Geophysics 18, 279-292.
Enfield, D., Mestas-Nuñez, A., Trimble, P., 2001. The Atlantic multidecadal oscillation and its relation to rainfall and river flows in the continental U.S. Geophysical Research Letters 28 (10), 2077-2080.

Ezer, T. and W. B. Corlett (2012). Is sea level rise accelerating in the Chesapeake Bay? A demonstration of a novel new approach for analyzing sea level data. Geophysical Research Letters 39 (19).

Ezer, T., L. P. Atkinson, W. B. Corlett and J. L. Blanco (2013). Gulf Stream's induced sea level rise and variability along the US mid-Atlantic coast. Journal of Geophysical Research: Oceans 118 (2), 685-697.

Ferla, M., M. Cordella, L. Michielli and A. Rusconi (2007). Long-term variations on sea level and tidal regime in the lagoon of Venice. Estuarine, Coastal and Shelf Science 75 (1), 214-222.

Gilbert, F., Dziewonski, A. M., 1975. An application of normal mode theory to the retrieval of structural parameters and source mechanisms from seismic spectra. Philosophical Transactions for the Royal Society of London. Series A, Mathematical and Physical Sciences, 187-269.

Grossmann, I. and P. J. Klotzbach (2009). A review of North Atlantic modes of natural variability and their driving mechanisms. Journal of Geophysical Research 114, 851-863.

Holgate, S. J., A. Matthews, P. L. Woodworth, L. J. Rickards, M. E. Tamisiea, E. Bradshaw, P. R. Foden, K. M. Gordon, S. Jevrejeva and J. Pugh (2012). New data systems and products at the Permanent Service for Mean Sea Level. Journal of Coastal Research 29 (3), 493-504.

Huang, N. E., Z. Shen, S. R. Long, M. C. Wu, H. H. Shih, Q. Zheng, N.-C. Yen, C. C. Tung and H. H. Liu (1998). The empirical mode decomposition and the Hilbert spectrum for nonlinear and non-stationary time series analysis. Proceedings of the Royal Society of London. Series A: Mathematical, Physical and Engineering Sciences 454 (1971), 903-995.

Hurrel, J. D. (1995). Decadal trends in the North Atlantic Oscillation: regional temperatures and precipitation. Science 269, 676-679.

Jevrejeva, S., A. Grinsted, J. Moore and S. Holgate (2006). Nonlinear trends and multiyear cycles in sea level records. Journal of Geophysical Research: Oceans (1978-2012) 111 (C9).

Jorda', G. and D. Gomis (2013). On the interpretation of the steric and mass components of sea level variability: The case of the Mediterranean basin. Journal of Geophysical Research: Oceans 118, 1-11.

Kay, S. (1988). Modern spectral estimation: theory and application. Englewood Cliffs, NJ.

Knight, J. R., Folland, C. K., Scaife, A. A., 2006. Climate 
impacts of the Atlantic multidecadaloscillation. Geophysical Research Letters 33 (17).

Landerer, F. W. and D. L. Volkov (2013). The anatomy of recent large sea level fluctuations in the mediterranean sea. Geophysical Research Letters 40 (3), 553-557.

Marcos, M. and M. N. Tsimplis (2007). Forcing of coastal sea level rise patterns in the North Atlantic and the Mediterranean Sea. Geophysical Research Letters 34 (18), C12028.

Masina, M. and A. Lamberti (2013). A nonstationary analysis for the Northern Adriatic extreme sea levels. Journal of Geophysical Research: Oceans 118, 1-18.

Olivieri, M. and G. Spada (2013). Intermittent sea-level acceleration. Global and Planetary Change 109, 64-72.

Pirazzoli, P. A. and A. Tomasin (2002). Recent evolution of surge-related events in the northern Adriatic area. Journal of Coastal Research 18 (3), 537-554.

Raicich, F. (2003). Recent evolution of sea-level extremes at Trieste (Northern Adriatic). Continental Shelf Research 23 (3), 225-235.

Raicich, F. (2012). Decadal variability of sea level in the Mediterranean Sea in connection with local climate and large-scale climate indicators. MedCLIVAR Conference, Madrid 26-28 September, Poster presentation.

Scafetta, N. (2013). Multi-scale dynamical analysis (MSDA) of sea level records versus PDO, AMO, and NAO indexes. Climate Dynamics, 1-18.

Scarascia, L. and P. Lionello (2013). Global and regional factors contributing to the past and future sea level rise in the Northern Adriatic Sea. Global and Planetary Change 106, 51-63.

Slangen, A. B. A., C. A. Katsman, R. S. W. Wal, L. L. A. Vermeersen and R. E. M. Riva (2011). Towards regional projections of twenty-first century sea-level change based on IPCC SRES scenarios. Climate Dynamics 38, 1191-1209.

Spada, G. G. Galassi (2012). New estimates of secular sea level rise from tide gauge data and GIA modelling. Geophysical Journal International 191 (3), 1067-1094.

Spada, G., G. Galassi and M. Olivieri (2014). A study of the longest tide gauge sea-level record in Greenland (Nuuk-Godthab, 1958-2002). Global and Planetary Change 118, 42-51.

Sturges, W. and B. Hong (2001). Decadal variability of sea level. In: Douglas, B. C., Kearney, M. S., Leatherman, S. P. (Eds.), Sea level rise: history and consequences. International Geophysics Series (75), pp. 165-180.

Suarez, M. J. and P. S. Schopf (1988). A delayed action oscillator for ENSO. Journal of the Atmo- spheric Sciences 45 (21), 3283-3287.
Sutton, R. T. and D. L. Hodson (2005). Atlantic Ocean forcing of North American and European summer climate. Science 309 (5731), 115-118.

Torres, M., M. A. Colominas, G. Schlotthauer and P. Flandrin (2011). A complete ensemble empir- ical mode decomposition with adaptive noise. In: Acoustics, Speech and Signal Processing (ICASSP), International Conference. IEEE, pp. 4144-4147.

Trupin, A. and J. Wahr (1990). Spectroscopic analysis of global tide gauge sea level data. Geophysi- cal Journal International 100 (3), 441-453.

Tsimplis, M. and T. Baker (2000). Sea level drop in the Mediterranean Sea: An indicator of deep water salinity and temperature changes? Geophysical Research Letters 27 (12), 1731-1734.

Tsimplis, M. N. and S. A. Josey (2001). Forcing of the Mediterranean Sea by atmospheric oscillations over the North Atlantic. Geophysical Research Letters 28 (5), 803-806.

Tsimplis, M. and M. Rixen (2002). Sea level in the Mediterranean Sea: The contribution of temperature and salinity changes. Geophysical Research Letters 29 (23), 51,1-51,4.

Tsimplis, M. N., F. Raicich, L. Fenoglio-Marc, A. G. P. Shaw, M. Marcos, S. Somot and A. Bergamasco (2012). Recent developments in understanding sea level rise at the Adriatic coasts. Physics and Chemistry of the Earth, Parts A/B/C 40-41.

Tsimplis, M. N., F. M. Calafat, G. Jordà, D. Gomis, L. Fenoglio-Marc, M. V. Struglia, S. A. Josey and D. P. Chambers (2013). The effect of the NAO on sea level and on mass changes in the Mediterranean Sea. Journal of Geophysical Research: Oceans 118 (2), 944-952.

Walter, K. and H. F. Graf (2002). On the changing nature of the regional connection between the North Atlantic Oscillation and sea surface temperature. Journal of Geophysical Research: Atmospheres 107 (D17), ACL-7.

Wessel, P. and W. H. F. Smith (1998). New, improved version of generic mapping tools released. Eos, Transactions American Geophysical Union 79 (47), 579.

$\mathrm{Wu}, \mathrm{Z}$. and N. E. Huang (2009). Ensemble empirical mode decomposition: a noise-assisted data analysis method. Advances in Adaptive Data Analysis 1 (01), 1-41.

\footnotetext{
${ }^{\star}$ Corresponding author: Gaia Galassi,

Università di Urbino, Dipartimento di Scienze di Base e Fondamenti (DiSBeF), Urbino, Italy; email: gaia.galassi@gmail.com.

C 2014 by the Istituto Nazionale di Geofisica e Vulcanologia. All rights reserved.
} 